\title{
Deep Burn Fuel Cycle Integration: Evaluation of Two-Tier Scenarios
}

S. Bays

H. Zhang

M. Pope

May 2009

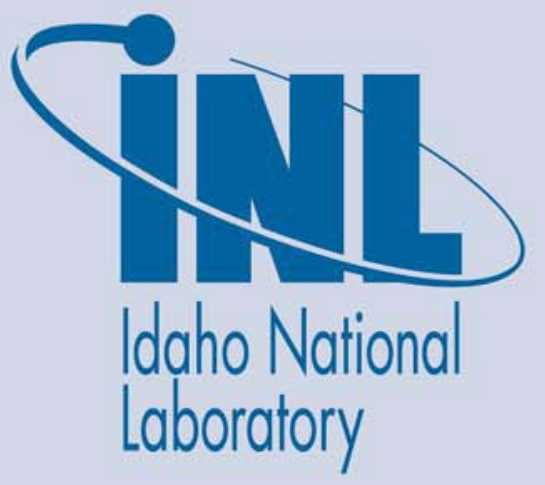

The INL is a U.S. Department of Energy National Laboratory operated by Battelle Energy Alliance 
INL/EXT-09-15915

\title{
Deep Burn Fuel Cycle Integration: Evaluation of Two- Tier Scenarios
}

\author{
S. Bays \\ H. Zhang \\ M. Pope
}

May 2009

\section{Idaho National Laboratory \\ Idaho Falls, Idaho 83415}

http://www.inl.gov

\author{
Prepared for the \\ U.S. Department of Energy \\ Office of Nuclear Energy \\ Under DOE Idaho Operations Office \\ Contract DE-AC07-05ID14517
}




\title{
Deep Burn Fuel Cycle Integration: Evaluation of Two-Tier Scenarios
}

\author{
INL/EXT-09-15915
}

May 2009

Approved by

Type 1st persons name here

Date

Type 2nd persons name here

Date

Type 3rd persons name here

Date 


\section{ABSTRACT}

The use of a deep burn strategy using VHTRs (or DB-MHR), as a means of burning transuranics produced by LWRs, was compared to performing this task with LWR MOX. The spent DB-MHR fuel was recycled for ultimate final recycle in fast reactors (ARRs). This report summarizes the preliminary findings of the support ratio (in terms of MWth installed) between LWRs, DB-MHRs and ARRs in an equilibrium "two-tier" fuel cycle scenario. Values from literature were used to represent the LWR and DB-MHR isotopic compositions. A reactor physics simulation of the ARR was analyzed to determine the effect that the DBMHR spent fuel cooling time on the ARR transuranic consumption rate.

These results suggest that the cooling time has some but not a significant impact on the ARRs conversion ratio and transuranic consumption rate. This is attributed to fissile worth being derived from non-fissile or "threshold-fissioning" isotopes in the ARR's fast spectrum.

The fraction of installed thermal capacity of each reactor in the DB-MHR 2-tier fuel cycle was compared with that of an equivalent MOX 2-tier fuel cycle, assuming fuel supply and demand are in equilibrium. The use of DB-MHRs in

the $1^{\text {st }}$-tier allows for a $10 \%$ increase in the fraction of fleet installed capacity of UO2-fueled LWRs compared to using a MOX $1^{\text {st }}$-tier. Also, it was found that because the DB-MHR derives more power per unit mass of transuranics charged to the fresh fuel, the "front-end" reprocessing demand is less than MOX. Therefore, more fleet installed capacity of DB-MHR would be required to support a given fleet of UO2 LWRs than would be required of MOX plants. However, the transuranic deep burn achieved by DB-MHRs reduces the number of fast reactors in the $2^{\text {nd }}$-tier to support the DB-MHRs "back-end" transuranic output than if MOX plants were used. Further analysis of the relative costs of these various types of reactors is required before a comparative study of these options could be considered complete. 



\section{CONTENTS}

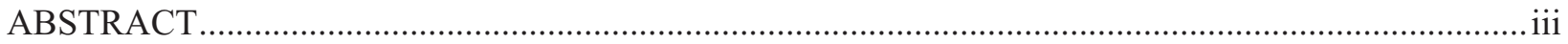

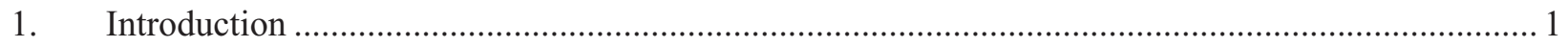

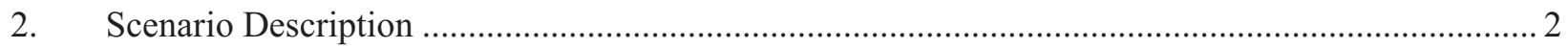

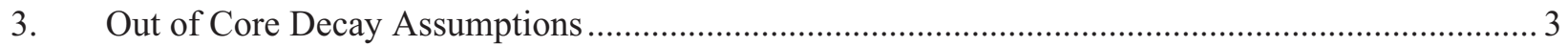

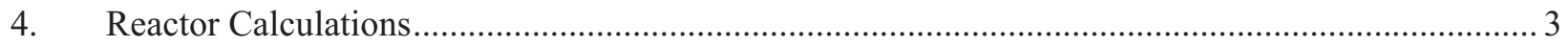

5. Effects of Cooling Time after DB-MHR Irradiation ................................................................. 4

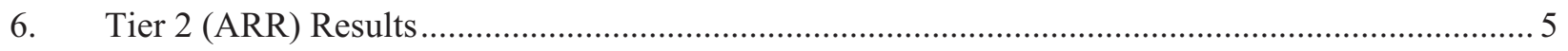

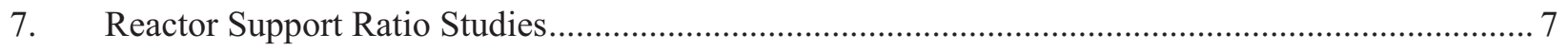

8. Minor Actinide Partitioning and Disposal Rates .................................................................. 8

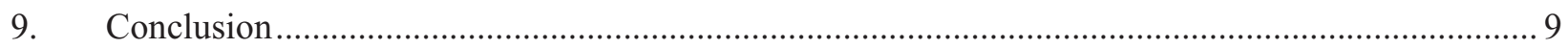

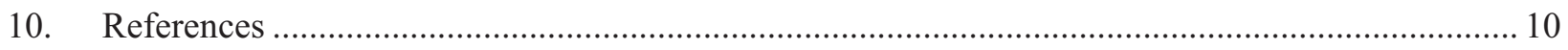

\section{FIGURES}

Figure 1: Two-tier DBMHR scenarios investigated in this work. ...................................................... 2

Figure 2: Core layout of: DB-MHR (A), and ARR (B) designs ..................................................... 4

Figure 3: Isotopic composition of ARR transuranic supply for DB-MHR Cases 1 and $2 \ldots \ldots \ldots \ldots \ldots \ldots \ldots . . . .4$

Figure 4: Transuranic charge, charge discharge and net consumption rates for UO2, MOX and DB-MHR7

Figure 5: Actinide separation streams for Case 2 minor actinide partitioning scenarios...... 9

\section{TABLES}

Table 1: DB-MHR charge and discharged isotopic concentrations from Ref. 2. . 1

Table 2: Values of time used in spent fuel and fabricated fuel decay times (in years) after residence in

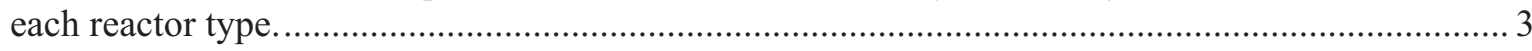

Table 3: Core average transuranic enrichments by volume fraction for ARR calculations........................ 5

Table 4: ARR consumption and recycling rates of TRU supplied by DB-MHR for the Case 1 scenario ... 5

Table 5: ARR consumption and recycling rates of TRU supplied by DB-MHR for the Case 2 scenario ... 6 
Table 6: ARR charge and discharged isotopic concentrations*

Table 7: Support ratio results of MWth-DBMHR/MWth-ARR (or MWth-MOX/MWth-ARR).............. 8

Table 8: Fractional breakdown of reactor thermal capacity in the reactor park: comparing MOX versus DB-MHR scenarios. 


\section{Deep Burn Fuel Cycle Integration: Evaluation of Two- Tier Scenarios}

\section{Introduction}

Growing interest in graphite moderated reactors fueled with fertile free transuranic-TRISO kernels (TRU-TRISO) has shown promising results for destroying the transuranic waste produced by Light Water Reactors (LWRs). These very high temperature graphite reactors (VHTR) have a potential to reach atomistic burnup in the range of 65 atom percent. The high temperature allows such systems to exhibit a high thermal efficiency for electricity generation compared to LWRs or other Generation-IV concepts such as the Sodium cooled Fast Reactor (SFR). Modular VHTR reactors using TRU-TRISO fuel that can attain this high transuranic destruction efficiency are dubbed Deep Burn-Modular Helium Reactors (DBMHR).

However, despite this high TRU transmutation efficiency, DB-MHR is a thermal reactor system. Therefore, the high transmutation efficiency is preferentially attributed to the destruction of fissile isotopes only. Therefore, the isotopic composition of DB-MHR is nearly depleted of fissile isotopes, i.e., $\mathrm{Pu}-239$ and $\mathrm{Pu}-241$. Thus, the DB-MHR spent fuel is highly concentrated in the remaining non-fissile plutonium isotopes and the minor actinides, also predominately non-fissile (Table 1). In thermal reactor spectra, including the harder graphite spectrum of DB-MHR, these isotopes have virtually zero ability to drive the chain-reaction. Therefore, sustained multi-recycling of TRU in DB-MHR may be unattractive.

Table 1: DB-MHR charge and discharged isotopic concentrations from Ref. 2.

\begin{tabular}{|c|c|c|}
\hline & Charge (w/o) & Discharge (w/o) \\
\hline $\mathrm{U}-234$ & & $0.30 \%$ \\
$\mathrm{U}-235$ & & $0.04 \%$ \\
$\mathrm{U}-236$ & & $0.02 \%$ \\
$\mathrm{~Np}-237$ & $6.79 \%$ & $6.90 \%$ \\
$\mathrm{Pu}-238$ & $2.90 \%$ & $15.79 \%$ \\
$\mathrm{Pu}-239$ & $49.44 \%$ & $2.50 \%$ \\
$\mathrm{Pu}-240$ & $22.97 \%$ & $14.69 \%$ \\
$\mathrm{Pu}-241$ & $8.79 \%$ & $13.29 \%$ \\
$\mathrm{Pu}-242$ & $4.89 \%$ & $28.99 \%$ \\
$\mathrm{Am}-241$ & $2.80 \%$ & $1.40 \%$ \\
$\mathrm{Am}-242 \mathrm{~m}$ & $0.02 \%$ & $0.07 \%$ \\
$\mathrm{Am}-243$ & $1.40 \%$ & $8.90 \%$ \\
$\mathrm{Cm}-242$ & & $0.60 \%$ \\
$\mathrm{Cm}-243$ & & $0.03 \%$ \\
$\mathrm{Cm}-244$ & & $6.00 \%$ \\
$\mathrm{Cm}-245$ & & $0.40 \%$ \\
$\mathrm{Cm}-246$ & & $0.08 \%$ \\
\hline
\end{tabular}

It has been proposed that after one, or possibly two-recycles, in DB-MHR, the TRU is recycled and irradiated in SFRs dedicated to sustained multi-recycling [1]. These reactors, dubbed Advanced Recycling Reactors (ARR), are not limited to only fissile isotopes to drive the chain reaction due to the fast threshold fission properties of non-fissile actinides. This two-tier scenario is similar to the LWR-toMOX-to-ARR scenario investigated by Ferrer et. al [2]. A two-tier fuel cycle is defined to be one where two separate fuel and/or reactor types are used to support waste burning of transuranics produced by the $0^{\text {th }}$-tier, LWRs. A single-tier fuel cycle has only one reactor/fuel combination for waste burning. In this 
paper, DB-MHR two-tier scenarios are compared to the single-tier and MOX two-tier scenarios investigated by Ferrer et. al.

\section{Scenario Description}

In this two-tier deployment scenario, the TRU from LWR (0-tier) Spent Nuclear Fuel (SNF) is recycled and fabricated into TRU-TRISO fuel (i.e., kernel, compact and fuel blocks). The TRU is irradiated in a DB-MHR (1 st-tier) until a 65 atom percent (at. \%) destruction is achieved. The DB-MHR is assumed to be the 5-ring, axial only shuffling, $200 \mu \mathrm{m}$ TRISO, concept devised by Kim et. al [3]. The DB-MHR spent fuel TRU is then recycled and submitted to the ARR's (2nd-tier) closed fuel cycle. The metal fueled core concept with a conversion ratio $(\mathrm{CR}=0.5)$, devised by Hoffman et. al., will be used as the reference ARR in this report [4]. The geometry of this reactor was adopted from Hoffman's CR=0.5 case and the CR was allowed to move with different TRU loadings analyzed in this work. Figure 1 shows the mass flow synergy between the various tiers of the two-tier fuel cycle. It is important to note that the DB-MHR study assumed that curium isotopes were partitioned from the SNF TRU. In the analyses that follow, it is assumed that:

- $\quad$ (Case 1) the curium mass from the $0^{\text {th }}$ tier is placed in interim storage during the duration of the $1^{\text {st }}$ tier leg of the fuel cycle and then irradiated in ARRs.

- (Case 2) the curium mass from the $0^{\text {th }}$-tier is disposed of in a geologic repository, as is the americium and curium resulting from the DBMHR $1^{\text {st }}$-tier.

In Case 1, the fuel cycle is self-consistent, meaning that all TRU produced by the reactor park is kept in the reactor park. In Case 2, curium is separated before TRU is irradiated in DB-MHRs, and both americium and curium are separated before TRU is irradiated in ARRs. These cases were chosen to quantify the minor actinide mass discharged from the fuel cycle (i.e., intermediate or geologic storage) if it is deemed technically non-viable from a fuel performance, fabrication, material handling or transportation standpoint to recycle these mass streams.
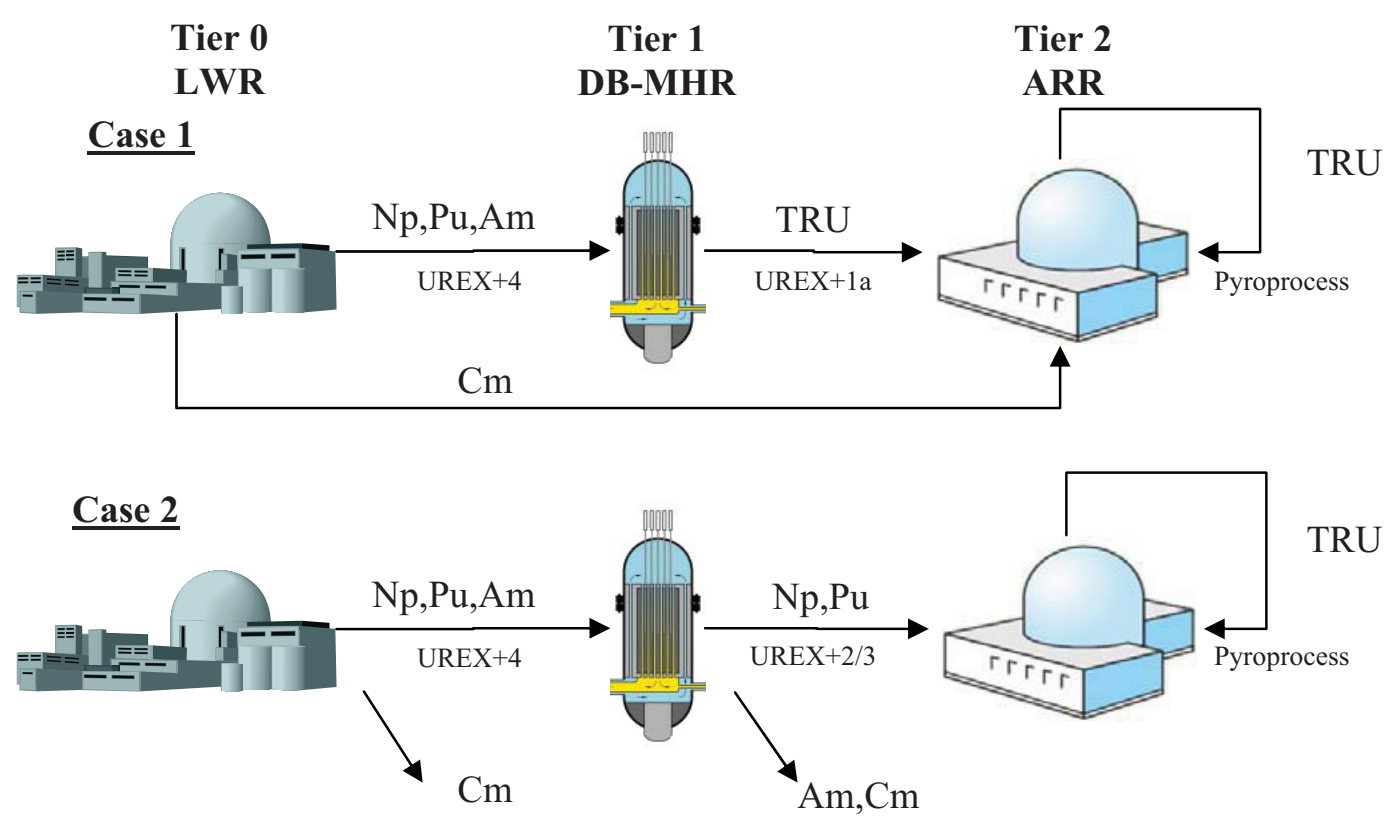

Figure 1: Two-tier DBMHR scenarios investigated in this work. 


\section{Out of Core Decay Assumptions}

Due to the high Pu-241 content of the discharged DB-MHR fuel, it is important to assess the perishabillity, due to $\mathrm{Pu}-241$ decay into $\mathrm{Am}-241$, of the $\mathrm{Pu}$ vector's reactivity worth. Though it is true that the SFR neutron spectrum allows for fission from non-fissile isotopes, fissile isotopes still offer more reactivity to the core. This is because much of the neutron spectrum in sodium cooled reactors exists at energies below the one-MeV threshold for fission. Therefore, a parametric study on the DB-MHR cooling time was conducted. Table 2 shows the time parameters used to decay spent fuel from one reactor type to the next.

Table 2: Values of time used in spent fuel and fabricated fuel decay times (in years) after residence in each reactor type.

\begin{tabular}{|c|c|c|}
\hline Reactor Type & $\begin{array}{c}\text { Spent Fuel Cooling } \\
\text { Time Before Separation }\end{array}$ & $\begin{array}{c}\text { Fabrication and Transportation } \\
\text { After Separation }\end{array}$ \\
\hline LWR (Tier 0) & 5 & 2 \\
DB-MHR (Tier 1) & $1,5,10,15,20$ & 2 \\
ARR (Tier 2) & 0.8 & 0.4 \\
\hline
\end{tabular}

The isotopic vector for various cooling/storage intervals was calculated using the ORNL code ORIGEN-S [5]. It is assumed that LWR SNF is decayed for five years before being recycled into DBMHR fuel. It is assumed that the DB-MHR spent fuel is decayed for 1, 5, 10, 15 or 20 years before being separated for recycling into ARR fuel. For both LWR SNF and DB-MHR spent fuel a post-separation time of two years is assumed to account for fabrication and transportation time to the reactor site. In the fast reactor (ARR), a cooling time and fabrication time of 0.8 and 0.4 years were assumed, respectively.

The curium interim storage time in Case 1 was assumed to be the sum of the LWR SNF cooling and fabrication times, the time the $\mathrm{Np}, \mathrm{Pu}, \mathrm{Am}$ component is irradiated in the $\mathrm{DB}-\mathrm{MHR}$, and the cooling and fabrication times after irradiation in the DB-MHR. The DB-MHR irradiation, from Kim et. al., is four cycles at 310 Effective Full Power Days (EFPD) each giving 3.4 years. Therefore, the curium decay times after 5 years of cooling and the two years following separation were 6.4, 10.4, 15.4, 20.4 and 25.4 years.

\section{Reactor Calculations}

For both the study by Kim et. al. and Hoffman et. al., the Tier-0 LWR SNF is assumed to have a burnup of $50 \mathrm{MWD} / \mathrm{kg}$. This assumption and resulting isotopic vector is used in generating the curium isotopic vector produced by LWRs in both Case 1 and Case 2.

Fresh and spent fuel compositions for the DB-MHR used in this work were taken from Kim et. al. (Table 1). The fast reactor calculations were conducted using the $M^{2}-2$, DIF3D-8, REBUS-3 code suite for the metal fueled ARR ( $\mathrm{CR}=0.5)$ core concept developed by Hoffman et. al. REBUS-3 was used to perform the core neutronics simulations, depletion, in-core fuel management and out-of-core fuel reprocessing operations pertinent to the ARR's closed fuel cycle $[6,7,8]$. These calculations were performed for each incremental cooling time from Table 2 for both Case 1 and Case 2 scenarios. Figure 2 depicts the lateral core layout of the DB-MHR and ARR designs, respectively. 


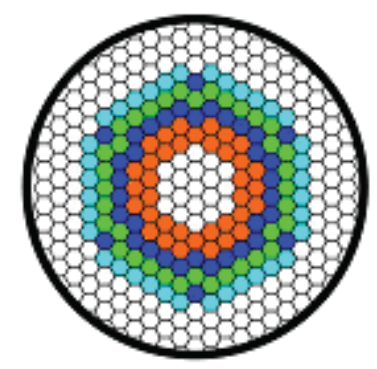

A

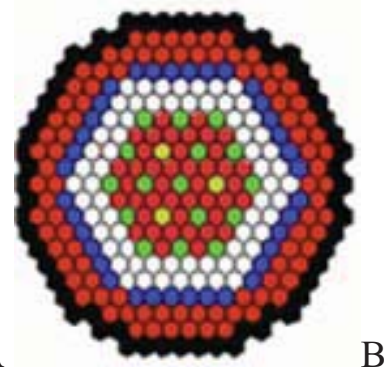

Figure 2: Core layout of: DB-MHR (A), and ARR (B) designs ${ }^{1}$

In Hoffman's analysis of the ARR conversion ratio, it was assumed that the conversion ratio could be reduced by reducing the uranium fraction while at the same time increasing the sodium fraction in the core. To first order, this assumes that the fuel assembly design would be altered to meet the conversion ratio requirement (i.e., decreasing fuel pin diameter). In this study, no optimization of the fuel dimensions or design was altered to meet a conversion ratio target. Also, just as in Hoffman's report, a fixed cycle length of 221 Effective Full Power Days (EFPD) was used.

\section{Effects of Cooling Time after DB-MHR Irradiation}

The duration of decay storage (i.e., cooling time) for the DB-MHR spent fuel directly impacts the concentration of Pu-241 and Am-241 in the ARR's transuranic fuel supply contributed by DB-MHR (Figure 3). In the Case 1 scenario, a longer cooling time leads to increasing concentrations of Am-241 and decreasing concentrations of $\mathrm{Pu}-241$. In the Case 2 scenario, americium (and curium) is removed from the transuranic mass stream before the final two-year decay time for fabrication and transportation. The result is a decreasing amount of Am-241 for increasing cooling times. The smaller Am-241 for increasing cooling times is due to less parent isotope, $\mathrm{Pu}-241$, at the beginning of the two-year decay period following recycle. It should be noted that the concentration of Am-241 in the Case 2 transuranic feed vector is contributed solely from decay of $\mathrm{Pu}-241$ after reprocessing. Hence, the concentration of americium is very small compared to Case 1 . The concentration of curium isotopes in Case 2 is zero.

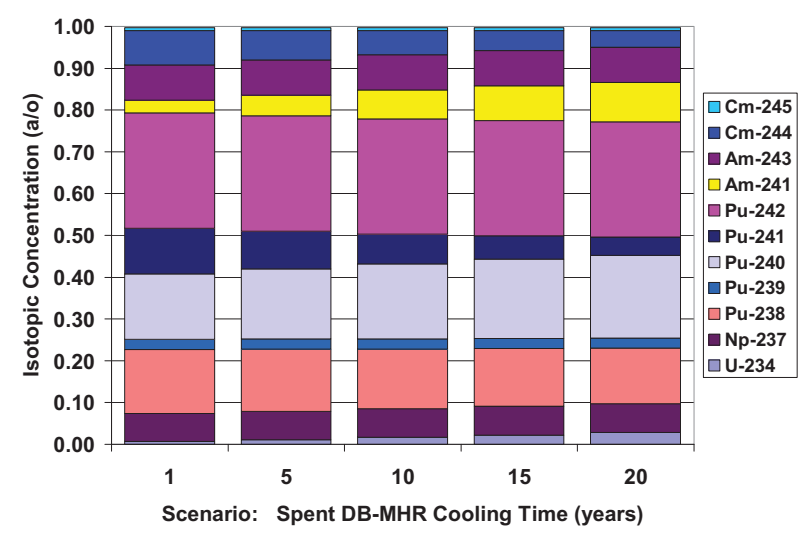

Case 1

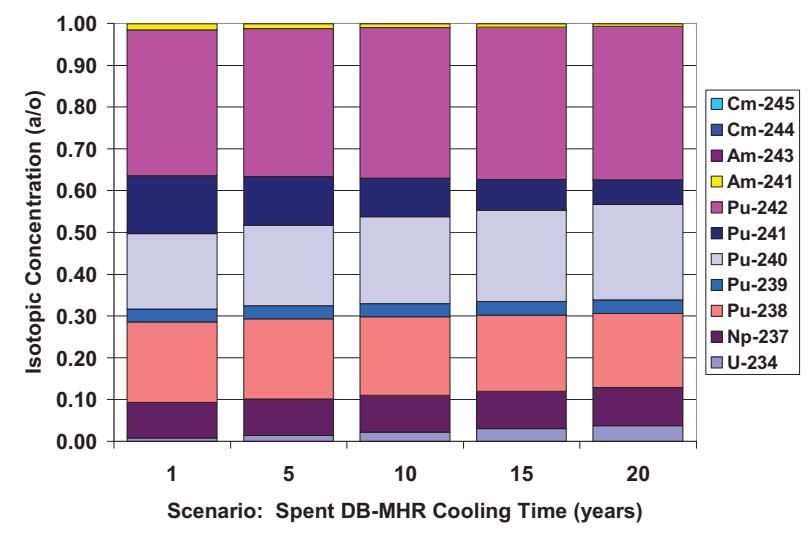

Case2

Figure 3: Isotopic composition of ARR transuranic supply for DB-MHR Cases 1 and $2^{2}$

\footnotetext{
${ }^{1}$ Images taken from Kim et. al. and Hoffman et. al., respectively [3,4].
} 
Because of the americium and curium separation, the Case 2 transuranic concentration is $\sim 25 \%$ richer in plutonium isotopes. The plutonium isotope most abundant in the DB-MHR discharge is $\mathrm{Pu}-242$ (Table 2). The higher concentration of this non-fissile plutonium isotope decreases the reactivity worth of the Case 2 transuranic feed vector to the ARR compared with Case 1. This lower reactivity worth requires that the Case 2 fresh fuel transuranic enrichments be slightly higher than that for the Case 1 scenarios (Table 3). In general, required ARR enrichments to achieve the desired thermal power and cycle length were around or slightly larger than $40 \%$. For comparison, the nominal equilibrium enrichment for the reference (homogeneous) ARR burning TRU produced by LWRs (i.e., single-tier) is $33.8 \%$ [4]. A similar two-tier analysis to the Case 1 scenario was performed by Ferrer et. al. using MOX (Pu-only) as the $1^{\text {st }}$-Tier Reactor providing TRU to the ARR [2]. The enrichment of the 2-tier ARR supported by MOX was found to be $36.4 \%$ and 33.6 for Case 1 and Case 2, respectively. It should be noted that in the Ferrer et. al. study, all minor actinides were discarded from all recycle stages in the Case 2 scenario of that work, which has the effect of lowering the ARR TRU enrichment requirements.

Table 3: Core average transuranic enrichments by volume fraction for ARR calculations

\begin{tabular}{|c|c|c|c|c|c|}
\hline DB-MHR Cooling Time (years) & 1 & 5 & 10 & 15 & 20 \\
\hline Case 1 & $39.6 \%$ & $40.1 \%$ & $40.8 \%$ & $41.4 \%$ & $41.8 \%$ \\
Case 2 & $41.5 \%$ & $42.0 \%$ & $42.5 \%$ & $43.0 \%$ & $43.0 \%$ \\
\hline
\end{tabular}

\section{6. $\quad$ Tier 2 (ARR) Results}

The increase in cooling times and the resulting accumulation of minor actinides in the DB-MHR spent fuel causes a decrease in the transuranic conversion ratio and a slight increase in the enrichment demand of the ARR as seen in Table 3. The increased enrichment has an effect to decrease conversion ratio while increasing the transuranic supply rate to the ARR. This transuranic supply can also be viewed as the rate at which TRU is consumed by the ARR's closed fuel cycle. In all cases, the effect of DBMHR cooling time has negligible effect on plutonium consumption rates (Table 4, Table 5). Instead, the transuranic consumption goes up to allow for an increasing amount of minor actinides present in the transuranic vector. The increase in enrichment for Case 2 slightly decreases the transuranic conversion ratio. This can also be seen by a generally larger transuranic consumption rate for Case 2 than in Case 1 .

The transuranic consumption rate of the reference ARR for the single-tier scenario is 173.8 g/MWY [4]. All of the DB-MHR two-tier cases consume transuranics at a higher rate. This can be explained by the differences in fissile quality of the DB-MHR versus the UO2 or MOX transuranic feeds.

Table 4: ARR consumption and recycling rates of TRU supplied by DB-MHR for the Case 1 scenario

\begin{tabular}{|c|c|c|c|c|c|c|}
\hline DB-MHR Cooling Time (years) & 1 & 5 & 10 & 15 & 20 & MOX \\
\hline TRU Conversion Ratio & 0.480 & 0.474 & 0.467 & 0.459 & 0.455 & 0.488 \\
\hline Actinide Consumption "DB-MHR/UREX+1a” Rates of the ARR (g/MWY) \\
\hline $\mathrm{Pu}$ & 129.9 & 129.5 & 129.5 & 129.7 & 129.5 & 129.0 \\
\hline $\mathrm{Np}, \mathrm{Pu}$ & 141.9 & 141.7 & 141.9 & 142.5 & 142.5 & 141.7 \\
\hline $\mathrm{Np}, \mathrm{Pu}, \mathrm{Am}$ & 162.9 & 166.5 & 170.7 & 174.5 & 177.1 & 164.4 \\
\hline $\mathrm{TRU}$ & 179.6 & 181.2 & 183.4 & 185.4 & 186.5 & 167.0 \\
\hline $\mathrm{Actinide}$ Recycling "ARR/Pyroprocess" Rates of the ARR (g/MWY) \\
\hline $\mathrm{Pu}$ & 713.6 & 722.6 & 733.4 & 743.3 & 750.2 & 640.7 \\
\hline $\mathrm{Np}, \mathrm{Pu}$ & 731.2 & 740.7 & 752.2 & 762.8 & 770.3 & 658.5 \\
\hline $\mathrm{Np}, \mathrm{Pu}, \mathrm{Am}$ & 835.2 & 849.9 & 867.1 & 882.9 & 894.2 & 729.5 \\
\hline $\mathrm{TRU}$ & 943.3 & 955.9 & 971.1 & 985.3 & 995.0 & 771.0 \\
\hline
\end{tabular}

\footnotetext{
${ }^{2}$ Isotopes with concentrations less than $\sim 0.1 \mathrm{a} / \mathrm{o}$ are not included in the figure.
} 
Table 5: ARR consumption and recycling rates of TRU supplied by DB-MHR for the Case 2 scenario ${ }^{3}$

\begin{tabular}{|c|c|c|c|c|c|c|}
\hline DB-MHR Cooling Time (years) & 1 & 5 & 10 & 15 & 20 & MOX \\
\hline TRU Conversion Ratio & 0.456 & 0.452 & 0.447 & 0.442 & 0.442 & 0.528 \\
\hline Actinide Consumption "DB-MHR/UREX+2/3" Rates of the ARR (g/MWY) \\
\hline $\mathrm{Pu}$ & 170.4 & 171.0 & 171.8 & 172.2 & 174.9 & 186.2 \\
\hline $\mathrm{Np}, \mathrm{Pu}$ & 186.4 & 187.5 & 188.8 & 189.8 & 193.2 & 186.2 \\
\hline $\mathrm{Np}, \mathrm{Pu}, \mathrm{Am}$ & 189.1 & 189.7 & 190.6 & 191.3 & 194.4 & 186.2 \\
\hline $\mathrm{TRU}$ & 189.1 & 189.7 & 190.6 & 191.3 & 194.4 & 186.2 \\
\hline $\mathrm{Actinide}$ Recycling "ARR/Pyroprocess" Rates of the ARR (g/MWY) \\
\hline $\mathrm{Pu}$ & 798.1 & 807.7 & 819.1 & 828.4 & 846.1 & 691.4 \\
\hline $\mathrm{Np}, \mathrm{Pu}$ & 820.6 & 830.8 & 843.1 & 853.3 & 872.2 & 691.4 \\
\hline $\mathrm{Np}, \mathrm{Pu}, \mathrm{Am}$ & 918.3 & 928.5 & 941.1 & 951.7 & 973.1 & 691.4 \\
\hline $\mathrm{TRU}$ & 987.8 & 999.1 & 1013.2 & 1025.0 & 1049.2 & 691.4 \\
\hline Actinides Sent to Repository Storage "by DB-MHR/UREX+2/3" (g/MWY) \\
\hline Minor Actinide & 40.1 & 43.2 & 46.5 & 49.1 & 51.1 & 47.5 \\
\hline
\end{tabular}

The amount of TRU internally recycled via pyroprocessing within the ARR's closed loop also goes up as the DB-MHR cooling time increases. This suggests that the plutonium vector is not significantly upgraded in fissile content as a result of being irradiated in the ARR (Table 6). In both cases, the Pu-239 concentration per transuranic increases by $\sim 15 \%$ during the course of the irradiation.

Table 6: ARR charge and discharged isotopic concentrations*

\begin{tabular}{|c|c|c|c|c|}
\hline & \multicolumn{2}{|c|}{ Case 1 } & \multicolumn{2}{c|}{ Case 2 } \\
\hline & Charge (w/o) & Discharge (w/o) & Charge (w/o) & Discharge (w/o) \\
\hline $\mathrm{U}-234$ & $1.60 \mathrm{E}-02$ & $1.58 \mathrm{E}-02$ & $1.97 \mathrm{E}-02$ & $1.93 \mathrm{E}-02$ \\
$\mathrm{U}-235$ & $5.21 \mathrm{E}-03$ & $4.67 \mathrm{E}-03$ & $5.77 \mathrm{E}-03$ & $5.47 \mathrm{E}-03$ \\
$\mathrm{U}-236$ & $8.84 \mathrm{E}-03$ & $9.25 \mathrm{E}-03$ & $9.02 \mathrm{E}-03$ & $9.59 \mathrm{E}-03$ \\
$\mathrm{~Np}-237$ & $2.66 \mathrm{E}-02$ & $1.90 \mathrm{E}-02$ & $3.31 \mathrm{E}-02$ & $2.31 \mathrm{E}-02$ \\
$\mathrm{Pu}-238$ & $7.30 \mathrm{E}-02$ & $6.00 \mathrm{E}-02$ & $8.36 \mathrm{E}-02$ & $6.50 \mathrm{E}-02$ \\
$\mathrm{Pu}-239$ & $1.74 \mathrm{E}-01$ & $2.02 \mathrm{E}-01$ & $1.65 \mathrm{E}-01$ & $1.90 \mathrm{E}-01$ \\
$\mathrm{Pu}-240$ & $2.16 \mathrm{E}-01$ & $2.23 \mathrm{E}-01$ & $2.15 \mathrm{E}-01$ & $2.18 \mathrm{E}-01$ \\
$\mathrm{Pu}-241$ & $4.17 \mathrm{E}-02$ & $3.57 \mathrm{E}-02$ & $4.62 \mathrm{E}-02$ & $3.70 \mathrm{E}-02$ \\
$\mathrm{Pu}-242$ & $2.27 \mathrm{E}-01$ & $2.18 \mathrm{E}-01$ & $2.87 \mathrm{E}-01$ & $2.73 \mathrm{E}-01$ \\
$\mathrm{Am}-241$ & $2.27 \mathrm{E}-02$ & $2.15 \mathrm{E}-02$ & $1.87 \mathrm{E}-02$ & $1.97 \mathrm{E}-02$ \\
$\mathrm{Am}-242 \mathrm{~m}$ & $1.48 \mathrm{E}-03$ & $1.64 \mathrm{E}-03$ & $1.18 \mathrm{E}-03$ & $1.40 \mathrm{E}-03$ \\
$\mathrm{Am}-243$ & $8.20 \mathrm{E}-02$ & $8.18 \mathrm{E}-02$ & $6.08 \mathrm{E}-02$ & $7.23 \mathrm{E}-02$ \\
$\mathrm{Cm}-242$ & $1.72 \mathrm{E}-04$ & $1.94 \mathrm{E}-04$ & $1.44 \mathrm{E}-04$ & $1.72 \mathrm{E}-04$ \\
$\mathrm{Cm}-243$ & $2.27 \mathrm{E}-04$ & $1.70 \mathrm{E}-04$ & $8.03 \mathrm{E}-05$ & $9.55 \mathrm{E}-05$ \\
$\mathrm{Cm}-244$ & $7.44 \mathrm{E}-02$ & $7.32 \mathrm{E}-02$ & $3.90 \mathrm{E}-02$ & $4.64 \mathrm{E}-02$ \\
$\mathrm{Cm}-245$ & $1.88 \mathrm{E}-02$ & $2.10 \mathrm{E}-02$ & $1.03 \mathrm{E}-02$ & $1.22 \mathrm{E}-02$ \\
$\mathrm{Cm}-246$ & $1.10 \mathrm{E}-02$ & $1.29 \mathrm{E}-02$ & $5.63 \mathrm{E}-03$ & $6.70 \mathrm{E}-03$ \\
\hline
\end{tabular}

*Averaged over each DB-MHR cooling time

\footnotetext{
${ }^{3} \mathrm{Cm}$ discharge rates from UO2/UREX +4 separations amounts to $0.7 \mathrm{~g} / \mathrm{MWY}$ which goes to interim storage for Case 1 or repository disposal in Case 2. The Am+Cm discharge rates from the DB-MHR/UREX+2/3 in Case 2 is 14.8, 12.6, 10.7, 9.1, 7.7 g/MWY for DB-MHR cooling times of 1, 5, 10, 15, 20 years, respectively.
} 


\section{Reactor Support Ratio Studies}

Due to its extremely high discharge burnup and TRU-only loading, the DB-MHR transuranic feed requirement per energy produced is actually less than that of MOX. The front end of the MOX fuel cycle requires the TRU produced by approximately 9 MWth of UO2 generation per 1 MWth of MOX generation (Figure 4). This is given a plutonium enrichment of $10 \%$ and a MOX burnup of $50 \mathrm{MWD} / \mathrm{kg}$. Therefore, although the net TRU destruction (in percent of loaded TRU) of MOX is less than that of DBMHR, its front-end reprocessing requirement is higher on a per MWth basis.

The DB-MHR front-end reprocessing requirement is lower per MWth. Here, the support ratio is based on the $\mathrm{Np}, \mathrm{Pu}, \mathrm{Am}$ instead of $\mathrm{Pu}$. The DB-MHR front-end support ratio was found to be about 6.7 MWth-UO2/MWth-DBMHR. It is also apparent from Figure 4 that the difference between the charge and discharge rates (i.e., the net consumption rate) of overall TRU is expectedly higher for DB-MHR than for MOX. An additional distinction is that the amount of net TRU destruction in MOX is much less than the net plutonium destruction. The difference in net destruction rates is from the net production of minor actinides. In the DB-MHR, the net TRU destruction is comparable to the net Pu destruction. This is partly due to the fact that the DB-MHR is loaded with the full minor actinide compliment (except Cm) from UO2 SNF. The addition of minor actinides to the fuel is allowable due to the fact that VHTR systems and TRU-TRISO fuels are not expected to suffer the same safety and fuel performance which limit minor actinide inclusion in LWR systems.

Table 7 shows the transuranic support ratio results for the ARR for the various DB-MHR cooling times for Case 1 and Case 2. In examining the support ratio trends there is little sensitivity to the reactor support ratio to the DB-MHR cooling time. This is to be expected given that the change in minor actinide concentration in the transuranic vector contributed only a small amount to the overall amount of transuranics being supplied to the core. The maximum increase in transuranic consumption for Case 1 was $4 \%$. The Case 2 transuranic feed and support ratios are almost completely insensitive to DB-MHR cooling time given the fact that the americium and curium produced during the decay cooling is separated only two years before the TRU is irradiated in the ARR. There is a large difference between the MOX support ratio and the DB-MHR ratio. This is attributable to the differences in the MOX and DB-MHR discharge rates. Given that the support ratio of DB-MHR's to ARR is not expected to be strongly dependent on the DB-MHR spent fuel cooling time. The results of the fast reactor study are averaged to compare the fractional breakdown of reactor thermal capacity in the reactor park (Table 8).

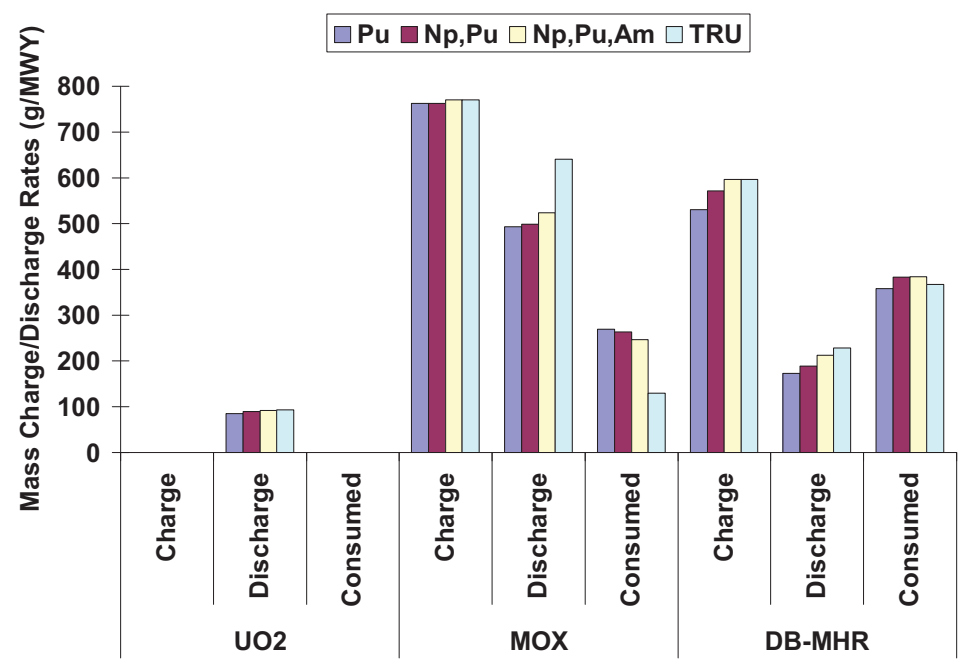

Figure 4: Transuranic charge, charge discharge and net consumption rates for UO2, MOX and DB-MHR 
Table 7: Support ratio results of MWth-DBMHR/MWth-ARR (or MWth-MOX/MWth-ARR)

\begin{tabular}{|c|c|c|c|c|c|c|c|c|c|c|c|c|}
\hline & \multicolumn{9}{c|}{ Case 1} & \multicolumn{6}{c|}{ Case 2} \\
\hline & 1 & 5 & 10 & 15 & 20 & MOX & 1 & 5 & 10 & 15 & 20 & MOX \\
\hline TRU & 0.78 & 0.79 & 0.80 & 0.81 & 0.81 & 0.26 & 0.83 & 0.83 & 0.83 & 0.84 & 0.85 & 0.29 \\
\hline
\end{tabular}

Table 8: Fractional breakdown of reactor thermal capacity in the reactor park: comparing MOX versus DB-MHR scenarios.

\begin{tabular}{|c|c|c|c|}
\hline & $0^{\text {th }}$-tier & $1^{\text {st }}$-tier & $2^{\text {nd }}$-tier \\
\hline & UO2 & MOX & ARR \\
\hline Case 1 & $63.1 \%$ & $7.6 \%$ & $29.3 \%$ \\
\hline Case 2 & $70.9 \%$ & $7.9 \%$ & $21.2 \%$ \\
\hline & UO2 & DB-MHR & ARR \\
\hline Case 1 & $74.2 \%$ & $11.5 \%$ & $14.4 \%$ \\
\hline Case 2 & $76.4 \%$ & $11.8 \%$ & $11.8 \%$ \\
\hline
\end{tabular}

It is interesting to note that the larger front-end reprocessing requirement of MOX allows a higher support ratio with UO2. Thus, if MOX is used, the $1^{\text {st }}$-tier will share a smaller fraction of the fleet than if DB-MHR is used. However, the MOX transuranic burning efficiency is much less than DB-MHR, thus its backend throughput is greater than DB-MHR. Therefore, if MOX is used, the 2nd-tier will share a larger fraction of the fleet than if DB-MHR is used. This savings in fast reactor support by the use of DBMHR allows for a larger fraction of the fleet being $0^{\text {th }}$-tier (i.e., UO2). The maximum increase in the UO2 share in the fleet made possible by using DB-MHR, as opposed to MOX, is about $10 \%$, which is observed for the Case 1 scenarios. If one considers that MOX is an LWR technology, the MOX and DBMHR scenarios will both have approximately the same share of LWR per Gen-IV installed thermal capacity within the fleet. Thus, the tradeoff of using DB-MHR in place of MOX as the $1^{\text {st }}$-tier recycling strategy in a 2-tier system is that it can reduce the number of MWth required by ARRs, but there must be more MWth of DB-MHR than there would have been from MOX.

Assuming the transuranic consumption rates reported by Hoffman et. al. and Ferrer et. al. for the reference ARR ( 170 g/MWY), a support ratio of 2 MWth-ARR/MWth-LWR. This gives a fleet fractional breakdown of $66 \%$ LWR and 33\% ARR.

\section{Minor Actinide Partitioning and Disposal Rates}

Unlike the Case 1 scenarios, Case 2 evaluates partitioning the minor actinide stream during reprocessing for repository disposal. It is interesting to note that the discharge rate of minor actinides from the DB-MHR fuel cycle is comparable, if not slightly less, than that of the MOX fuel cycle (Figure 5). This is mainly attributed to two factors. First, the DB-MHR reactor is not only a plutonium burner as is MOX, but is also a slightly net minor actinide burner. Second, the DB-MHR transuranic discharge rate is much less than that of MOX, thus the $\mathrm{Am}+\mathrm{Cm}$ discharge rate is correspondingly less. 

Tier 0
LWR
Tier 1
MOX or DB-MHR
Tier 2
ARR
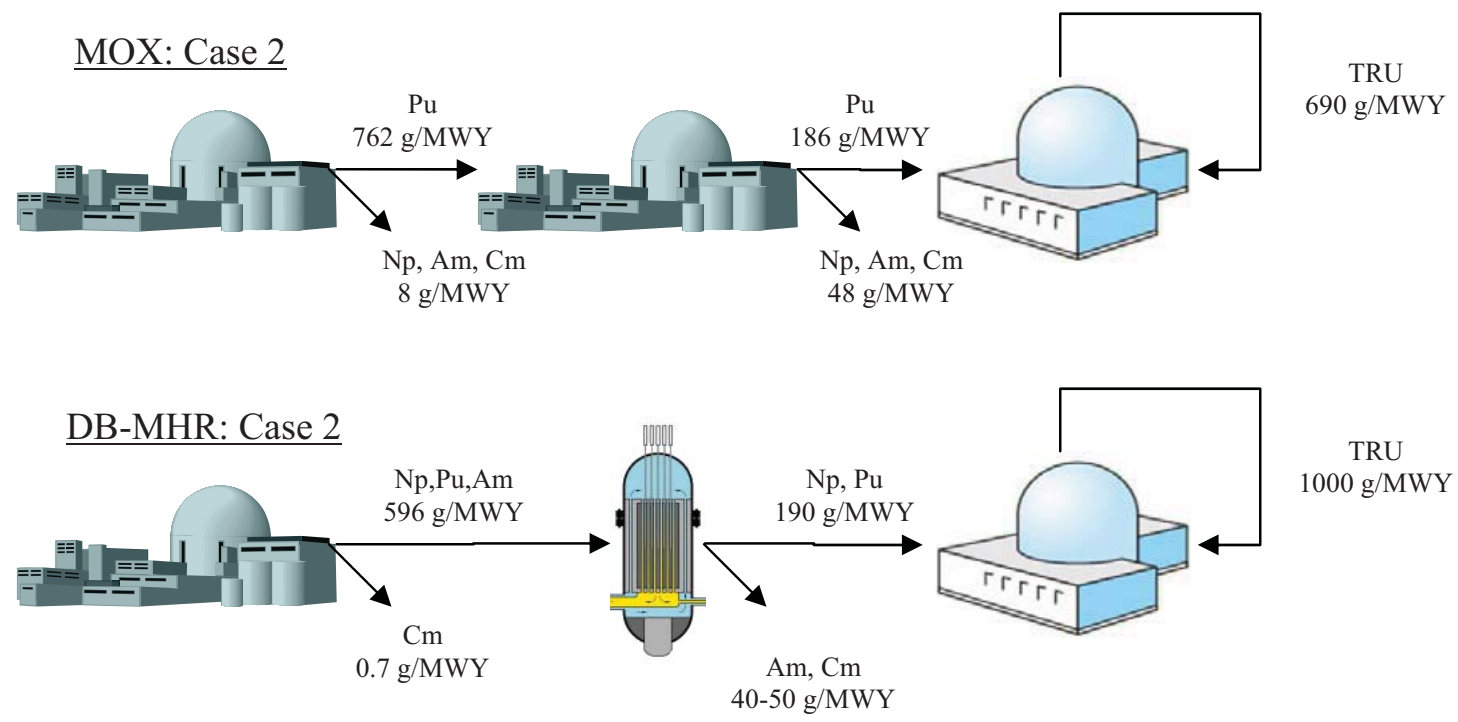

Figure 5: Actinide separation streams for Case 2 minor actinide partitioning scenarios

\section{Conclusion}

The use of a deep burn strategy using VHTRs (or DB-MHR) as a means of burning transuranics produced by LWRs as the $1^{\text {st }}$ tier in a 2-tier scenario, was compared to performing this task with MOX. It was found that the high transuranic destruction efficiency of deep burn allowed for a reduction in the number of fast reactors in the two-tier fuel cycle, relative to using MOX. Also, the use of DB-MHRs allowed a $10 \%$ increase in the fraction of capacity in the park which would come from UO2-fueled LWRs. However, because the charging rate of TRU into a MOX plant is greater than that of a DB-MHR on a per MWth basis, more thermal capacity of DB-MHR would be required to support a given fleet of UO2 LWRs than would be required of MOX plants. Additionally, the deep burn achieved by DB-MHR reduces the TRU discharged from the $1^{\text {st }}$-tier, thus less ARR's are needed in the $2^{\text {nd }}$-tier to support the back-end of the fuel cycle. Further analysis of the relative costs of these various types of reactors is required before a comparative study of these options could be considered complete.

Sensitivity studies on the DB-MHR spent fuel cooling time on the fissile quality of transuranics going to the ARR and the resulting changes in the ARR front-end transuranic throughput. It was observed that an increase in the DB-MHR cooling time did lead to higher ARR transuranic consumption as a result of $\mathrm{Pu}-241$ beta decay into Am-241. This decay is a loss of a fissile atom in the ARR transuranic feed. However, despite an observable trend, this perishabillity effect was not significant enough to greatly affect the transuranic consumption rate of the ARR.

In non-self-consistent scenarios, where minor actinides from LWR SNF and DB-MHR spent fuel are partitioned and discharged to a repository from the fuel cycle, the cooling time did have some effect on how much minor actinide was discharged from the system. The difference between a 1 year and a 20 year cooling time amounted to an americium and curium discharge rate of $40 \mathrm{~g} / \mathrm{MWY}$ and $50 \mathrm{~g} / \mathrm{MWY}$, respectively. 


\section{References}

1. General Atomics, "GNEP Deployment Studies: Executive Summary," GA Project 30293, PC000555, rev. 3, (2008)

2. R. FERRER, S. BAYS, M. POPE, "Evaluation of Homogeneous Options: Effects of Minor Actinide Exclusion from Single and Double Tier Recycle in Sodium Fast Reactors," INL/EXT-0814034, (2008)

3. Y. KIM AND F. VENNERI, "Optimization of One-Pass Transuranic Deep Burn in a Modular Helium Reactor," Nuclear Science and Engineering, 160, 59-74, (2008)

4. E. HOFFMAN, W. YANG, R. HILL, "Preliminary Core Design Studies for the Advanced Burner Reactor Over a Range of Conversion Ratios," ANL-AFCI-177, (2006)

5. I. GAULD, O. HERMAN, R. WESTFALL, ORIGEN-S: Scale System Module to Calculate, Fission Product Buildup and Decay, and Associated Radiation Source Terms, ORNL-2005/39, Version 5.1, Volume II, Book 1, Section F7, (2006)

6. H. HENRYSON II, B. TOPPEL, C. STENBERG, "MC2-2: A Code to Calculate Fast Neutron, Spectra and Multi-Group Cross-Sections," ANL-8144, (1976)

7. K. DERSTINE, DIF3D: "A Code to Solve One-, Two-, and Three-Dimensional Finite-Difference Diffusion Theory Problems," ANL-82-64, (1984)

8. B. TOPPEL, “A User's Guide to the REBUS-3 Fuel Cycle Analysis Capability,” ANL-83-2, (1983) 